\title{
ANALISIS KEPATUHAN PERAWAT DALAM MELAKSANAKAN STANDAR PROSEDUR OPERASIONAL PEMASANGAN VENTILATOR DI RUMAH SAKIT PKU MUHAMMADIYAH YOGYAKARTA
}

\author{
Maria Ulfa ${ }^{1}$, Fiqih Adhyaksafitri ${ }^{2}$ \\ 1. Department of Public Health, Universitas Muhammadiyah Yogyakarta \\ 2. Student of Medical and Health Science, Universitas Muhammadiyah Yogyakarta \\ Email :mariaulfa@umy.ac.id//missmariaulfa@gmail.com
}

\begin{abstract}
Abstrak
Latar belakang: Penerapan standar prosedur operasional (SPO) pemasangan ventilator adalah salah satu upaya pencegahan dan pengendalian infeksi. Pelaksanaan SPO bergantung pada kepatuhan perawat yang dapat bervariasi karena dipengaruhi oleh seperti faktor internal (jenis kelamin, pengetahuan, dan sikap) serta faktor eksternal (karakteristik kelompok dan pekerjaan).

Tujuan Penelitian: Untuk mengetahui tingkat kepatuhan perawat, serta hubungan dan pengaruh faktor internal dan faktor eksternal terhadap kepatuhan perawat dalam melaksanakan SPO pemasangan ventilator di RS PKU Muhammadiyah Yogyakarta.

Metode: Penelitian ini adalah analitik observasional dengan pendekatan cross-sectional yang hasilnya disajikan secara deskriptif dilanjutkan analisis bivariat dan analisis multivariat. Subjek penelitian adalah perawat ruang ICU RS PKU Muhammadiyah Yogyakarta. Instrumen penelitian ini adalah kuesioner dan checklist observasi yang juga dicocokkan dengan lembar wawancara.

Hasil dan Pembahasan: Sikap, pengetahuan, dan faktor eksternal memberikan kontribusi terhadap kepatuhan perawat sebesar 34,4\% dan sikap merupakan faktor yang berpengaruh terhadap kepatuhan perawat.

Kesimpulan: Beberapa perawat masih tidak mematuhi SPO sepenuhnya, rekomendasi yang perlu dilakukan adalah meningkatkan kepatuhan perawat dengan cara meningkatkan monitoring, memberikan pelatihan dan motivasi perawat dalam mematuhi SPO pemasangan ventilator.
\end{abstract}

Kata Kunci: kepatuhan perawat, standar prosedur operasional pemasangan ventilator 


\begin{abstract}
Background: Implementation of ventilator installment's standard operational procedure (SOP) is a way to prevent and control infection. It depends on the nurse's compliance which is influenced by internal factors (gender, knowledge, and attitude) and external factors (characteristic of the group and work).

Objective: To determine the level of nurse's compliance, also the correlation and effect of internal and external factors to the nurse's compliance on ventilator installment's SOP in Yogyakarta PKU Muhammadiyah Hospital.

Methods: This study was an observational analytical with cross-sectional approach of which results were presented in descriptive followed by bivariate and multivariate analysis. The subjects were nurses in the ICU of Yogyakarta PKU Muhammadiyah Hospital. The research instruments were a questionnaire, a checklist, and an interview sheet.

Results and Discussion: The attitude affected the nurse's compliance. Attitude, knowledge, and external factors together contributed in nurse's compliace on ventilator installment's SOP of 34,4\%.

Conclusion: Some nurses did not execute the ventilator installment's SOP properly, recommendations needed to do were improving the nurse's compliance by increasing monitoring, giving both a training and motivation of nurses in the compliance of ventilator installment's SOP.
\end{abstract}

Keywords: the compliance of nurse, standard operational procedure of ventilator

\section{PENDAHULUAN}

Pemasangan ventilator atau ventilasi mekanik secara invasif adalah salah satu tindakan medis untuk mengatasi kondisi kritis pasien gagal napas yang dirawat di unit perawatan intensif (ICU). ${ }^{4}$ Proses pemasangan ventilator yang tidak sesuai prosedur dapat meningkatkan risiko terjadinya Ventilator Associated Pneumonia (VAP) yang merupakan infeksi nosokomial paling banyak terjadi di ICU. ${ }^{8}$ Kejadian infeksi dapat menurunkan citra dan mutu pelayanan rumah sakit karena program pengendalian infeksi nosokomial merupakan salah satu tolak ukur kendali mutu pelayanan. ${ }^{6}$ Rumah Sakit PKU Muhammadiyah Yogyakarta adalah rumah sakit yang telah terakreditasi penuh dengan fasilitas yang cukup lengkap, salah satunya adalah fasilitas perawatan intensif (ICU). ${ }^{14}$ Peningkatan kebutuhan masyarakat akan pelayanan kesehatan perlu diimbangi dengan evaluasi dan peningkatan manajemen mutu terutama dalam pencegahan infeksi. Infeksi nosokomial akan berdampak tidak hanya dari segi medis bagi pasien, namun juga dari segi ekonomis yakni biaya rumah sakit yang ditanggungnya. ${ }^{24}$
Intervensi dari segenap petugas kesehatan khususnya perawat dalam program pencegahan dan pengendalian infeksi dapat dilakukan dalam bentuk kepatuhan terhadap standar prosedur operasional (SPO) tindakan medis termasuk pemasangan ventilator yang telah ditetapkan rumah sakit. ${ }^{13}$ Perilaku kepatuhan dapat bervariasi disebabkan oleh beberapa faktor yakni faktor internal yaitu karakteristik perawat itu sendiri dan faktor eksternal. ${ }^{2}$ Menurut Pierre et al (2015), pengendalian VAP ini perlu mendapat perhatian khusus oleh sarana kesehatan dalam memberikan pelayanan kepada pasien dan karena ketidakpatuhan sebagai suatu masalah medis yang berat. ${ }^{27}$ maka penelitian tentang kepatuhan perawat dalam melaksanakan standar prosedur operasional (SPO) pemasangan ventilator di Rumah Sakit PKU Muhammadiyah Yogyakarta perlu dilakukan.

\section{BAHAN DAN CARA}

Penelitian ini menggunakan rancangan observasional analitik dengan menggunakan rancangan pendekatan cross sectional yang dilaksanakan di Rumah Sakit PKU Muhammadiyah Yogyakarta pada bulan Maret 2015 sampai Mei 2015. Sampel penelitian ini adalah perawat tetap yang bekerja di ruang ICU RS PKU

Vol. 1 No. 2 Juli 2015 
Muhammadiyah Yogyakarta. Pengambilan sampel digunakan metode Consecutive Sampling yaitu teknik pengambilan sampel berdasarkan kriteria yang telah ditetapkan sebelumnya. ${ }^{17}$ Besar sampel setelah dihitung sebesar 30 .

Instrumen penelitian berupa kuesioner untuk mengumpulkan data mengenai karakteristik demografis, pengetahuan, sikap dan faktor eksternal responden. Checklist observasi tindakan pemasangan ventilator digunakan untuk menilai kepatuhan. Data dianalisis secara univariat, bivariat untuk melihat ada tidaknya hubungan atau kemaknaan secara statistik ditunjukkan dari hasil uji korelasi Spearman dan Lambda. dan multivariat untuk menentukan variabel bebas yang mempengaruhi variabel terikat menggunakan uji regresi linier berganda. Tingkat kepercayaan yang digunakan
95\% dan $\mathrm{P}<0,05$, artinya hipotesis akan diterima dan keeratan hubungan antarvariabel dinyatakan dalam koefisien korelasi (r). ${ }^{3}$

HASIL

\section{Hasil Analisis Univariat}

\section{Gambaran Umum Lokasi Penelitian}

Rumah Sakit (RS) PKU Muhammadiyah Yogyakarta Unit I memiliki kapasitas ruang ICU sebanyak 6 tempat tidur (bed) dengan 14 orang perawat sedangkan Unit II memliki 15 bed dengan 16 orang perawat. Ventilator pada RS PKU Muhammadiyah Yogyakarta Unit I sebanyak 2 buah, sedangkan Unit II memiliki 1 buah.

\section{Hasil Analisis Univariat Responden}

Tabel 1. Hasil Analisis Univariat Responden

\begin{tabular}{|c|c|c|c|}
\hline V ariabel & Kategori Variabel & Jumlah & $\begin{array}{c}\text { Persentase } \\
(\%)\end{array}$ \\
\hline \multirow{3}{*}{ Jenis Kelamin } & Laki-laki & 7 & 23,3 \\
\hline & Perempuan & 23 & 76,7 \\
\hline & Total & 30 & 100,0 \\
\hline \multirow{3}{*}{ Umur } & $=35$ tahun & 20 & 66,7 \\
\hline & $<35$ tahun & 10 & 33,3 \\
\hline & Total & 30 & 100,0 \\
\hline \multirow{3}{*}{ Masa Kerja } & $=10$ tahun & 18 & 60,0 \\
\hline & $<10$ tahun & 12 & 40,0 \\
\hline & Total & 30 & 100,0 \\
\hline \multirow{3}{*}{$\begin{array}{c}\text { Tingkat } \\
\text { Pendidikan }\end{array}$} & D III & 22 & 73,3 \\
\hline & S1 & 8 & 26,7 \\
\hline & Total & 30 & 100,0 \\
\hline \multirow{3}{*}{ Pengetahuan } & Baik & 21 & 70,0 \\
\hline & Kurang & 9 & 30,0 \\
\hline & Total & 30 & 100,0 \\
\hline \multirow{3}{*}{ Sikap } & Baik & 25 & 83,3 \\
\hline & Kurang & 5 & 16,7 \\
\hline & Total & 30 & 100,0 \\
\hline \multirow{3}{*}{$\begin{array}{c}\text { Faktor } \\
\text { Eksternal }\end{array}$} & Baik & 24 & 80,0 \\
\hline & Kurang & 6 & 20,0 \\
\hline & Total & 30 & 100,0 \\
\hline \multirow{3}{*}{ Kepatuhan } & Patuh & 24 & 80,0 \\
\hline & Tidak Patuh & 6 & 20,0 \\
\hline & Total & 30 & 100,0 \\
\hline
\end{tabular}

Sumber: Data primer 
Skor sikap responden memiliki nilai minimum dan maksimum sebesar 64,44 - 96,67, dengan rerata sebesar 84,22 dan simpang baku 9,38. Skor pengetahuan responden memiliki nilai minimum dan maksimum sebesar 68,18 - 95,45, dengan rerata sebesar 85,0 dan simpang baku 10,48. Skor faktor eksternal responden memiliki nilai minimum dan maksimum sebesar 72,50 93,75, dengan rerata sebesar 80.38 dan simpang baku 6 ,2. Skor kepatuhan responden memiliki nilai minimum dan maksimum sebesar 72,22 - 94,44, dengan rerata sebesar 85,74 dan simpang baku 8,08. Tabel di atas menunjukkan persentase dari faktor-faktor tersebut apabila dikonversikan menjadi kategori berjenjang.

\section{Hasil Analisis Bivariat}

Analisis bivariat dilakukan untuk mengetahui hubungan faktor internal (jenis kelamin, pengetahuan, dan sikap) serta faktor eksternal terhadap kepatuhan perawat dalam melaksanakan standar prosedur operasional (SPO) pemasangan ventilator di Rumah Sakit PKU Muhammadiyah Yogyakarta, dengan menggunakan uji Spearman Rho Rank dan uji Lambda dengan tingkat kemaknaan 95\% (á = 0.05). Keeratan dan sifat hubungan diketahui dari nilai $r$ pada uji korelasi tersebut.

\section{Hasil Analisis Uji Spearman Rho Rank}

Tabel 2. Hasil Analisis Uji Spearman Rho Rank

\begin{tabular}{|c|c|c|}
\hline \multirow{2}{*}{ Sikap } & \multicolumn{2}{c|}{ Kepatuhan } \\
\hline \multirow{2}{*}{ Pengetahuan } & $\boldsymbol{P}$ & 0,71 \\
\cline { 2 - 3 } & $\mathbf{N}$ & 0,00 \\
\hline \multirow{3}{*}{ Faktor Eksternal } & $\boldsymbol{R}$ & 0,46 \\
\cline { 2 - 3 } & $\boldsymbol{P}$ & 0,01 \\
\cline { 2 - 3 } & $\mathbf{N}$ & 30 \\
\hline \multirow{3}{*}{} & $\boldsymbol{R}$ & 0,36 \\
\cline { 2 - 3 } & $\boldsymbol{P}$ & 0,048 \\
\cline { 2 - 3 } & $\mathbf{N}$ & 30 \\
\hline
\end{tabular}

Sumber: Data primer

Hasil analisis menunjukkan bahwa terdapat hubungan antara sikap, pengetahuan, dan faktor eksternal dengan kepatuhan perawat dalam melaksanakan standar prosedur operasional (SPO) pemasangan ventilator di RS PKU Muhammadiyah Yogyakarta. Berdasarkan nilai $r$ dapat diketahui bahwa sikap memiliki keeratan hubungan yang kuat, pengetahuan memiliki keeratan hubungan yang sedang, dan faktor eksternal memiliki keeratan hubungan yang lemah terhadap kepatuhan perawat dalam melaksanakan SPO pemasangan ventilator.

\section{Hasil Analisis Uji Lambda}

Hasil analisis menunjukkan bahwa nilai signifikasi (p) antara jenis kelamin dengan kepatuhan adalah 0,818. Nilai p >0,05, sehingga dapat disimpulkan bahwa tidak terdapat hubungan antara jenis kelamin dengan kepatuhan perawat dalam melaksanakan SPO pemasangan ventilator.

\section{Hasil Analisis Multivariat}

Analisis multivariat digunakan untuk menganalisis variabel mana yang paling berpengaruh terhadap kepatuhan perawat dalam melaksanakan SPO pemasangan ventilator, sehingga skor kepatuhan perawat dapat diprediksikan berdasarkan faktor yang mempengaruhinya. Tiga variabel bebas (sikap, pengetahuan dan faktor eksternal) diuji dengan uji regresi linier berganda untuk mengetahui variabel mana yang berpengaruh terhadap kepatuhan perawat. Berikut hasil analisis multivariat: 
Uji $t$

Uji t ini digunakan untuk menunjukkan pengaruh secara individu variabel bebas yang ada didalam model terhadap variabel terikat.

Tabel 3. Hasil Uji t

\begin{tabular}{|l|c|c|c|}
\hline Variabel & $\begin{array}{c}\mathbf{t} \text { hitung } \\
(\boldsymbol{t})\end{array}$ & \multirow{2}{*}{$\mathbf{t}$ table } & $\begin{array}{c}\text { Signifikansi } \\
(\boldsymbol{p})\end{array}$ \\
\hline Konstanta & 1,6983 & \multirow{4}{*}{2.052} & 0,101 \\
\hline Pengetahuan & 0,683 & & 0,500 \\
\hline Sikap & 2,093 & \multirow{2}{*}{2.05} & 0,046 \\
\hline Faktor Eksternal & 0,845 & & 0,406 \\
\hline
\end{tabular}

Sumber: Data primer

Terdapat pengaruh variabel sikap sedangkan pengetahuan dan faktor eksternal tidak berpengaruh secara parsial terhadap kepatuhan perawat.

\section{Uji Linieritas dengan Uji F}

Tabel 4. Hasil Uji F

\begin{tabular}{|c|c|c|c|c|}
\hline Model & $\begin{array}{c}\text { Koefisien Korelasi } \\
(\mathbf{r})\end{array}$ & Koefisien Determinasi $\left(\mathbf{r}^{2}\right)$ & Adjusted $\mathbf{r}^{2}$ & Durbin-Watson \\
\hline 1 & 0,642 & 0,412 & 0,3344 & 2,677 \\
\hline
\end{tabular}

Sumber: Data primer

Terdapat pengaruh yang signifikan antara sikap, pengetahuan, dan faktor eksternal secara simultan terhadap kepatuhan perawat dalam melaksanakan SPO pemasangan ventilator di RS PKU Muhammadiyah Yogyakarta.

\section{Koefisien Determinasi $\left(\mathbf{r}^{2}\right)$}

Tabel 5. Hasil Koefisien Determinasi

\begin{tabular}{|c|c|c|c|c|}
\hline Model & Df & $\begin{array}{c}\text { F hitung } \\
(\mathbf{F})\end{array}$ & F tabel & $\begin{array}{c}\text { Signifikansi } \\
(\boldsymbol{p})\end{array}$ \\
\hline Regression & 3 & \multirow{2}{*}{6,070} & \multirow{2}{*}{2,98} & \multirow{2}{*}{0,003} \\
\cline { 1 - 2 } Residual & 26 & 6,070 & & \\
\hline Total & 29 & & \\
\hline
\end{tabular}

Sumber: Data primer

Hasil analisis menunjukkan bahwa sikap, pengetahuan, dan faktor eksternal memberikan kontribusi terhadap kepatuhan perawat dalam melaksanakan SPO pemasangan ventilator di RS PKU Muhammadiyah Yogyakarta sebesar 34,4\%. 


\section{Uji Regresi Linier Berganda}

Tabel 6. Hasil Analisis Multivariat Regresi Linier

Berganda

\begin{tabular}{|c|c|c|c|}
\hline & Variabel & Koefisien & $\begin{array}{c}\text { Signifikansi } \\
(\boldsymbol{p})\end{array}$ \\
\hline \multirow{4}{*}{$\mathbf{1}$} & Konstanta & 28.231 & 0,101 \\
\cline { 2 - 4 } & Pengetahuan & 0,116 & 0,500 \\
\cline { 2 - 4 } & Sikap & 0,390 & 0,046 \\
\cline { 2 - 4 } & $\begin{array}{c}\text { Faktor } \\
\text { Eksternal }\end{array}$ & 0,184 & 0,406 \\
\hline
\end{tabular}

Sumber: Data primer

Analisis regresi linier berganda dilakukan dengan metode enter, dan diperoleh hasil bahwa variabel bebas yakni sikap berpengaruh untuk memprediksikan kepatuhan perawat.

\section{DISKUSI}

\section{Karakteristik Responden}

Jumlah perawat di Ruang Intensive Care Unit (ICU) Rumah Sakit (RS) PKU Muhammadiyah Yogyakarta yang berjenis kelamin laki-laki. lebih sedikit dibandingkan dengan perawat perempuan. Hasil penelitian ini memiliki kesamaan dengan teori yang dikemukakan bahwa jenis kelamin perawat didominasi oleh perempuan, karena dalam sejarahnya keperawatan muncul sebagai peran care taking (pemberi perawatan) secara tradisional di dalam keluarga dan masyarakat. ${ }^{21}$

Mayoritas perawat berada di rentang usia lebih dari atau sama dengan 35 tahun. Hal ini menunjukkan bahwa perawat berada pada rentang umur dewasa tengah baya, yang mana pada usia tersebut seseorang sedang berambisi untuk meraih puncak karir mereka antara usia 35-50 tahun sehingga mereka akan memliki kecenderungan untuk bekerja dengan maksimal. ${ }^{9}$

Berdasarkan hasil penelitian menunjukkan bahwa mayoritas perawat mempunyai masa kerja lebih dari sama dengan 10 tahun (60\%). Ini menunjukkan bahwa perawat relatif sudah cukup berpengalaman. Semakin lama masa kerja perawat, maka pengalamannya dalam menjalankan tugas di bidang keperawatan akan semakin meningkat.
Kebanyakan perawat adalah lulusan diploma tiga (DIII). Hasil penelitian ini sesuai dengan penelitian Soeroso (2003), yang menyatakan lebih dari 60\% perawat masih berpendidikan DIII di Indonesia. Kesadaran dari perawat diperlukan untuk memikirkan tindak lanjut pendididikannya agar eksistensi mereka dalam pelayanan keperawatan di era globalisasi saat ini dapat dipertahankan dan ditingkatkan.

Menurut Sunaryo (2012), sikap adalah kesiapan merespons yang sifatnya positif atau negatif terhadap suatu objek atau situasi secara konsisten. Beberapa perawat memiliki sikap yang tergolong kurang, dalam hal ini mungkin tidak tepat respon perawat dalam hal pemasangan ventilator.

Hasil penelitian menunjukkan bahwa sebagian besar responden memiliki pengetahuan baik (70\%) tentang ventilator. Beberapa perawat memiliki faktor eksternal yang kurang. Hal ini dapat terjadi bila terdapat pembagian pekerjaan yang tak sesuai yang akhirnya menjadi beban. Kepala ruangan maupun pihak rumah sakit sebaiknya mencermati hal ini agar dapat mengantisipasi terjadinya kejenuhan pada perawat, yang dapat menurunkan produktivitasnya.

Pelaksanaan standar prosedur operasional (SPO) pemasangan ventilator di Rumah Sakit PKU Muhammadiyah Yogyakarta oleh perawat dapat dikatakan belum maksimal karena hanya $80 \%$ perawat yang patuh. Poin nomor 10, yakni poin mengenai penggantian sarung tangan di sela tindakan pada checklist kepatuhan adalah poin yang paling sering terlewatkan oleh perawat ketika melakukan pemasangan 
ventilator. Poin 4 (menutup tirai atau pintu kamar pasien), 11 (memasukkan alat laringoskopi untuk memasukkan pipa ETT), dan 16 (membuka tirai atau pintu) juga menyusul sebagai poin yang terlewatkan oleh beberapa perawat.

Peneliti melakukan wawancara kepada perawat yang melewatkan poin dalam checklist untuk mengetahui alasan perawat. Perawat mengatakan bahwa penggantian sarung tangan steril di tengah-tengah pelaksanaan pemasangan ventilator memang bukan prosedur rutin dan juga akan memakan waktu. Pergantian sarung tangan steril sebaiknya dilakukan karena bagaimanapun juga hal ini akan mengurangi risiko transmisi mikroorganisme dari sarung tangan sebelumnya yang mungkin sudah terkontaminasi. Beberapa perawat juga sering melewatkan menutup tirai pasien, dan ketika diwawancarai mereka mengatakan bahwa penutupan tirai tidak akan mempengaruhi kondisi pasien. Namun, menurut peneliti penutupan tirai ini meskipun tidak mempengaruhi kondisi pasien tetapi adalah salah satu tindakan kita dalam menghormati privasi pasien.

Pelaksanaan SPO yang paling mendasar adalah poin mengenai kewaspadaan universal. Tindakan pengendalian infeksi ini mencakup mencuci tangan untuk meminimalisir risiko transmisi mikroorganisme. Sesuai hasil observasi peneliti, tindakan mencuci tangan perawat lebih seringnya dilakukan dengan menggunakan hand rub dan peneliti jarang mendapati perawat mencuci tangan dengan air mengalir dan sabun. Praktek cuci tangan menurut penelitian Desiyanto (2013)menunjukkan bahwa memberikan perbedaan jumlah koloni kuman di tangan yang bermakna jika dibandingkan dengan menggunakan hand $r u b$ ataupun tidak mencuci tangan. Alangkah lebih baik bila perilaku mencuci tangan perawat dievaluasi kembali, agar angka infeksi nosokomial dapat dikendalikan.

Beberapa perawat tidak melakukan tindakan intubasi dengan pipa endotrakeal/ETT, ketika ditelusuri ternyata alasannya adalah karena beberapa perawat tersebut memang tidak melakukan tindakan intubasi dan tindakan tersebut merupakan tugas perawat yang lain. Dapat disimpulkan bahwasanya terdapat ketumpangtindihan karena ada beberapa perawat yang melakukan tindakan intubasi sedangkan lainnya tidak.

\section{Hubungan antara Faktor Internal dan Eksternal terhadap Kepatuhan Perawat dalam Melaksanakan Standar Prosedur Operasional (SPO) Pemasangan Ventilator}

Berdasarkan hasil penelitian, terdapat hubungan antara sikap, pengetahuan, dan faktor eksternal dengan kepatuhan perawat. Sebaliknya, tidak terdapat hubungan antara jenis kelamin dengan kepatuhan perawat.

\section{Hubungan Faktor Internal dengan Kepatuhan}

Hasil penelitian mirip dengan penelitian Ince Maria (2011) yang menunjukkan bahwa mayoritas responden adalah berjenis kelamin perempuan. Pendekatan psikologis menyatakan bahwa wanita lebih patuh pada aturan dan otoritas. ${ }^{25}$ Namun, pada penelitian ini peneliti tidak mendapatkan adanya hubungan yang bermakna antara jenis kelamin dengan kepatuhan. Artinya, hasil penelitian ini bertolakbelakang dengan teori yang telah dikemukakan di awal.

Responden ada yang memiliki sikap positif maupun negatif dalam penelitian ini dapat disebabkan oleh berbagai faktor, yakni faktor pengalaman pribadi dan faktor emosional. ${ }^{28}$ Sikap belum merupakan suatu tindakan atau aktivitas, akan tetapi merupakan predisposisi tindakan suatu perilaku. ${ }^{18}$

Tingkat pengetahuan perawat tidak semuanya mempunyai pengetahuan dengan kategori baik. Hal ini diduga dikarenakan perbedaan tingkat pendidikan dan pengalaman. Pendidikan akan mempengaruhi seseorang dalam mengambil keputusan sehingga semakin tinggi tingkat pendidikan seseorang semakin mengerti dan memahami tentang sesuatu ilmu serta akan berpengaruh pada perilakunya, sehingga perilaku kepatuhannya akan lebih tinggi. Umur dan masa kerja perawat berkaitan dengan pengalaman selama melakukan praktek yang akan berdampak pada pengetahuan tentang ventilator . 18

Hasil penelitian ini sejalan dengan hasil penelitian yang dilakukan oleh Kusriyati (2006) yang 
menyimpulkan bahwa pengetahuan perawat yang baik akan diikuti oleh meningkatnya keterampilan perawat dalam pemasangan infus di ruang rawat inap RSUD Cilacap.

\section{Hubungan Faktor Eksternal dengan Kepatuhan}

Perawat sebagai anggota kelompok melaksanakan peran tugas, peran pembentukan, pemeliharaan kelompok, dan peran individu. Anggota melaksanakan hal ini melalui hubungan interpersonal. Tekanan dari kelompok sangat erat kaitannya dengan hubungan interpersonal dan tingkat kepatuhan individu. Lingkungan kerja yang nyaman dan menyenangkan harus diciptakan sehingga perawat dapat bekerja dengan tenang dan konsentrasi, sehingga dapat meningkatkan produktivitas kerja. ${ }^{29}$ Kondisi lingkungan tempat kerja perawat mempengaruhi perilaku perawat untuk menjadi patuh, hal ini mungkin berkaitan dengan kenyamanan perawat. Sesuai dengan penelitian yang dilakukan oleh Setiyawati, (2010) yang menyatakan bahwa kondisi lingkungan di rumah sakit mempengaruhi kenyamanan kerja perawat. Beban kerja dapat menurunkan motivasi perawat untuk menjadi patuh. Hal ini mungkin disebabkan adanya perasaan jenuh dalam diri perawat sehingga perawat menjadi kurang produktif.

\section{Faktor yang Berpengaruh terhadap Kepatuhan Perawat}

Hasil analisis dengan uji regresi linier berganda menunjukkan bahwa sikap berpengaruh terhadap kepatuhan perawat dalam melaksanakan SPO pemasangan ventilator. Hal ini berbeda dengan hasil penelitian yang dilakukan oleh Herpan (2012) yang menunjukkan bahwa variabel yang paling dominan berhubungan dengan kinerja perawat dalam pengendalian infeksi nosokomial adalah variabel pengetahuan. Demikian pula dengan penelitian. ${ }^{5}$

Hubungan dan pengaruh antara variabel bebas dari faktor internal dan eksternal dengan kepatuhan perawat dalam melaksanakan standar prosedur operasional (SPO) pemasangan ventilator perlu untuk diketahui karena apabila beberapa variabel seperti pengetahuan, sikap dan faktor eksternal seorang perawat tersebut kurang maka dapat menimbulkan hal yang membahayakan bagi diri sendiri maupun bagi pasien. Apabila memang benar terdapat hubungan dan pengaruh di antara keduanya, maka peningkatan variabel bebas yang memiliki hubungan dengan kepatuhan perawat dapat digunakan sebagai salah satu cara untuk meningkatkan kualitas penerapan perilaku patuh terhadap SPO pemasangan ventilator.

Peningkatan pengetahuan dan sikap perawat dapat dicapai dengan mengadakan program pengembangan perawat, misalnya dengan pelatihan. Peningkatan faktor eksternal seperti pembagian kerja yang lebih merata, atau peningkatan infrastuktut dapat membantu menghindarkan perawat dari kejenuhan.

\section{KESIMPULAN}

Penelitian ini memberikan beberapa kesimpulan, yang pertama adalah ada hubungan yang bermakna antara sikap, pengetahuan dan faktor eksternal, namun tidak ada hubungan antara jenis kelamin dengan kepatuhan perawat dalam melaksanakan standar prosedur operasional (SPO) pemasangan ventilator. Semakin baik sikap, pengetahuan dan faktor eksternal maka perawat akan semakin patuh. Kedua, pengaruh dari sikap terhadap kepatuhan perawat dalam melaksanakan SPO pemasangan ventilator. Sejak awal hingga akhir penelitian dapat disimpulkan bahwa beberapa perawat tidak patuh, tidak memiliki pengetahuan dan sikap yang baik, serta mengeluhkan adanya beban kerja. Hal ini tentunya memerlukan eksplorasi lebih lanjut dan solusi untuk mengatasinya.

\section{SARAN}

Rumah Sakit PKU Muhammadiyah Yogyakarta sebaiknya melakukan evaluasi kembali tentang pengaturan dan pelaksanaan SPO pemasangan ventilator. Seluruh perawat hendaknya meningkatkan kesadarannya untuk selalu bekerja sesuai dengan SPO terutama dalam melakukan prosedur steril. Manajemen RS PKU Muhammadiyah Yogyakarta harus memberi perhatian khusus kepada perawat yang mengeluhkan adanya beban kerja, untuk mengetahui kemungkinan adanya rasa jenuh pada perawat tersebut. Diharapkan kepada pihak RS untuk melakukan pelatihan kepada perawat terutama tentang pelaksanaan SPO 
pemasangan ventialator dan memberikan motivasi kepada perawat untuk senantiasa patuh.

Kepada peneliti selanjutnya mungkin dapat melakukan penelitian tentang kepatuhan dalam melaksanakan standar prosedur operasional (SPO) pemasangan ventilator bukan hanya pada perawat tetapi juga petugas kesehatan lainnya, misalnya dokter.

Setiap penelitian pasti memiliki beberapa keterbatasan. Peneliti menyadari adanya kekurangan pada penelitian mengenai kepatuhan perawat dalam melaksanakan SPO pemasangan ventilator di RS PKU Muhammadiyah Yogyakarta. Pemasangan ventilator merupakan tindakan medis yang relatif jarang dilakukan bila dibandingkan dengan pemasangan infus atau kateter, sehingga peneliti sedikit mengalami kesulitan dalam mengumpulkan data hingga sesuai jumlah yang diperlukan.

\section{DAFTAR PUSTAKA}

1. Amanda, F. 2012. Faktor- Faktor yang Berhubungan dengan Ibu Hamil dalam Mengonsumsi Tablet Zat Besi di Wilayah Kerja Puskesmas Tanah Garam Kota Solok Tahun 2012. Padang: Universitas Andalas.

2. Andares. 2009. Analisa Hubungan Karakteristik Perawat dan Tingkat Kepatuhan Perawat dalam Pelaksanaan Protap Pemasangan Infus di Rumah Sakit Badrul Aini Medan. Medan. Skripsi : Tidak dipublikasikan.

3. Arikunto, S. 2012. Prosedur Penelitian Suatu Pendekatan Praktek. Jakarta: Rineka Cipta.

4. Beckers, S. K., Brokmann, J. C., Rossaint, R. 2014. Airway and Ventilator Management in Trauma Patients. Current Opinion in critical Care Volume 20 Issue 6: p626-631.

5. Choiriyah. 2010. Faktor-Faktor yang Mempengaruhi Tindakan Perawat dalam Upaya Pencegahan Infeksi Nosokomial di Ruang Rawat Inap RSI Surakarta. (Skripsi Tidak dipublikasikan).

6. Departemen Kesehatan RI. 2011. Pedoman Pencegahan dan Penanggulangan Infeksi di Rumah Sakit dan Fasilitas Kesehatan Lainnya. Jakarta: DepKes
7. Desiyanto, F.A. \& Djannah S.N. 2013. Efektivitas Mencuci Tangan Menggunakan Cairan Pembersih Tangan Antiseptik (Hand Sanitizer) Terhadap Jumlah Angka Kuman. Kesmas. Volume 7. Nomor 2. September 2013. ISSN: 1978-0575. Yogyakarta: Universitas Ahmad Dahlan Yogyakarta.

8. El-Saed. A., Balkhy, H.H., Alansari, H., et al. 2015. Rates of Ventilator-Associated Pneumonia in Critical Care Units in Three Arabian Gulf Countries; Six Year Surveillance Study. (Online), (http:// www.ncbi.nlm.nih.gov, diakses 4 Februari 2015)

9. Gunarsa, S.D. 2011. Dari Anak Sampai Usia Lanjut: Bunga Rampai Psikologi Perkembangan. Jakarta: PT BPK Gunung Mulia.

10.Hamishekar, H., Shadvar, K., Mahmoodpoor, A., et al. 2014. Ventilator-Associated Pneumonia in Patients Admitted to Intensive Care Units, Using Open or Closed Endotracheal Suctioning. Anesth Pain Med Volume 4 Issue 5.

11.Hartati, dkk. 2007. Hubungan Tingkat Pengetahuan Perawat dengan Keterampilan Melaksanakan Prosedur Tetap Isap Lendir/Suction di Ruang ICU RSUD Prof. Dr. Margono Soekarjo Purwokerto. Jurnal Keperawatan Soedirman (The Soedirman Journal of Nursing), Volume 2, No.1, Maret 2007. Purwokerto: Universitas Jendral Soedirman.

12.Herpan, Y. W. 2012. Analisis Kinerja Perawat dalam Pengendalian Infeksi Nosokomial di RSU PKU Muhammadiyah Bantul Yogyakarta. Kesmas Voume. 6, No. 3, September 2012. Yogyakarta: Universitas Ahmad Dahlan.

13. Iosifidis, E., Stabouli, S., Tsolaki, A., et al. 2015. Diagnosing Ventilator-Associated Pneumonia in Pediatric Intensive Care. American Journal of Infection Control Volume 43 Issue 4: p. 390-393

14. Kollef, M.H. 2015. Ventilator-Associated Pneumonia: The Role of Emerging Therapies and Diagnostics.CHEST Journal. (Online), (http:// journal.publications.chestnet.org, diakses tanggal 14 Februari 2015)

15. Kusriyati. 2006. Gambaran Kemampuan Perawat Menurut Persepsi Pasien dalam Tindakan Pemasangan Infus di Ruang Rawat Inap RSUD Cilacap Tahun 2005. Karya Tulis Ilmiah. Program 
Studi D III Kebidanan Sekolah Tinggi Ilmu Kesehatan (STIKES) Al-Irsyad AlIslamiyyah Cilacap.

16.Maria, I. 2012. Kepatuhan Perawat Dalam Melaksanakan Standar Prosedur Operasional Pemasangan Infus Terhadap Phlebitis. Jurnal STIKES Volume 5, No.1, Juli 2012. Kediri: STIKES BAPTIS.

17.Notoatmodjo, S. 2010. Pendidikan dan Perilaku Kesehatan. Jakarta: Rineka Cipta.

18.Notoatmodjo, S. 2012. Metodologi Penelitian Kesehatan. Jakarta: Rineka Cipta.

19.Nursalam. 2012. Konsep dan Penerapan Metode Penelitian Ilmu Keperawatan, Ed. 2. Jakarta: Salemba Medika.

20.Pierre, D., Frederic, F., Arnaud, A., et al. 2015. Prevention of Ventilator-Associated Pneumonia and Ventilator-Associated Conditions : A Randomized Controlled Trial with Subglottic Secretion Suctioning. Critical Care Medicine Volume 43 Issue 1: p. 22-30.

21.Rollinson, D \& Kish 2010. Care Concept in Advanced Nursing. St. Louis: Mosby A Harcourt Health Science Company.

22.Setiyawati. 2010. Proses Pembelajaran dalam Pendidikan Kesehatan. Jakarta: TIM.

23.Soeroso, S. 2003. Manajemen Sumber Daya Manusia Di Rumah Sakit Suatu Pendekatan Sistem. EGC. Jakarta.

24.Soni, R., Mehta, K., Sheth, K., et al. 2014. Influence of Ventilator-Associated Pneumonia on Cost of Hospitalization for Patient Requiring Mechanical Ventilation: A Nationwide Analysis. Europe PubMed Central. (Online), (http://www.europepmc.org, diakses tanggal 6 Maret 2015)

25.Subkhi, A \& Jauhar, M. 2013. Pengantar Teori dan Perilaku Organisasi. Jakarta: Prestasi Pustaka.

26.Sunaryo. 2012. Psikologi untuk Keperawatan. Jakarta: EGC
27.Swamy, A.A., Prabhu, S. S., Fernandes, N., 2014. A Study to Access the Practices of Staff Nurses Regarding Care of Children on Ventilator. Asian Journal of Multidisciplinary Studies Volume 2, Issue 9, September 2014.

28.Wawan, A. \& Dewi, M. 2010. Teori dan Pengukuran Pengetahuan Sikap dan Perilaku Manusia. Yogyakarta: Penerbit Nuha Medika.

29.Widayatun, T.R. 2011. Ilmu Perilaku. Jakarta: Infomedik. 